This is a pre-peer review version of the paper submitted to the journal Progress in Photovoltaics. It has been selected by the Executive Committee of the 28th EU PVSEC 2013 for submission to Progress in Photovoltaics.

\title{
VALUE OF NET-FIT PV POLICIES FOR DIFFERENT ELECTRICITY INDUSTRY PARTICIPANTS CONSIDERING DEMAND SIDE RESPONSE
}

\author{
Sebastián Oliva and Iain MacGill \\ School of Electrical Engineering and Telecommunications and Centre for Energy and Environmental Markets \\ The University of New South Wales, Sydney, NSW2052, Australia. \\ Tel.: +61 449978022, Fax: +61 293855993. E-mail: s.olivahenriquez@student.unsw.edu.au
}

\begin{abstract}
Net-FiT policies for residential PV have financial implications not only for PV customers but all other electricity industry participants. They may also incentivise households to adjust their daily load patterns to either minimise or maximise PV export depending on the FiT design, and wider retail electricity arrangements. In this paper we study the financial implications of both residential PV systems and such demand-side response (DSR) on the financial returns of PV for households, their retailers and their distribution network service providers (DNSPs). We use half-hourly PV generation and household consumption data for 60 houses in the Australian city of Sydney, and consider two net-FiT designs offering tariffs either significantly higher or lower than retail electricity rates. We use a simple model of DSR which allows households to increase PV exports or self-consumption by moving load between daylight hours and the evening. We find such DSR modestly improve household revenue, but has potentially greater implications for retailers and DNSPs. DSR to increase exports reduces the adverse impacts of PV on retailer and DNSP revenues, whilst increased self-consumption worsens them. Conversely, increased exports might drive DNSP expenditures in constrained network areas while increased self-consumption might help reduce them. The study highlights the importance of designing PV policies with regard to their implications for retailers and DNSPs as well as PV households. Furthermore, the broader policy settings of retail electricity markets will become increasingly important as PV deployment grows, opportunities for DSR expand, and current inadequacies in retail electricity markets become more marked.
\end{abstract}

Keywords: Feed-in tariffs, household PV systems, net metering, demand side response

\section{INTRODUCTION}

Photovoltaics (PV) has experienced remarkable growth in deployment over the past decade driven by falling system costs and supportive government policies in a number of countries. Around 140 countries have implemented policies to support renewable power generation with many of these including measures targeted towards PV. Feed-in tariffs (FiTs) which provide a premium 'tariff' for eligible renewable generation have been the most widely implemented policy mechanism, and were in place in more than 71 countries and 28 states/provinces worldwide in early 2013 [1].

In Australia a number of States have implemented net metering Feed-in-Tariffs (net-FiTs) for small residential solar systems that pay a PV specific tariff for any PV generation that exceeds customer demand. Initially these States introduced relatively attractive net-FiT schemes with PV 'export' tariffs significantly higher than standard retail tariffs [2, 3]. Under such circumstances, PV generation consumed by the household is effectively worth less than if it is exported to the grid. Given very rapid PV deployment in these States, however, policy makers have increasingly been specifying net-FiTs for exported PV generation that are significantly lower than retail tariffs. They have argued that retail tariffs include a significant network component, and that PV generation typically doesn't reduce the network costs of serving a household [2]. As such, the real value of exported PV generation to a PV customer's retailer is much closer to wholesale electricity prices than the retail tariff. Under such circumstances, of course, self-consumed PV generation is now more valuable to a household than that which is exported. One might expect very different financial implications of these two tariff approaches for PV customers, retailers, and Distribution Network
Service Providers (DNSPs) [4]. Furthermore, and as explored in this paper, customers with PV systems will face very different financial incentives with regard to how they might manage electrical loads whose operation can be shifted across different time periods. Indeed, such Demand-Side Response (DSR) might prove highly valuable to such customers.

Targeted PV policies of recent years have been introduced into a diverse, highly uncertain, rapidly changing and complex policy context. The societal and private value of $\mathrm{PV}$ has been rapidly changing with falling PV costs and broader electricity industry changes including, in many jurisdictions, growing environmental concerns, increasing peak demand and hence network expenditure, and retail market changes. While FiT policies have played a critical role in PV deployment and hence cost reductions, some jurisdictional efforts have created an extremely compelling financial case for energy users leading to unexpected and, in some cases, overwhelming rates of installations. As a consequence, existing FiTs have been revised over recent years in many countries including France, Germany, Italy, Spain and the UK [1, 5] and other jurisdictions [6-8]. In Australia, the FiTs Solar Bonus Scheme (SBS) implemented in the state of New South Wales (NSW) led, in conjunction with Federal Government support and falling PV prices, to the deployment of over 150,000 PV systems in little more than a year [2]. By comparison, total NSW household PV systems numbered some 2900 in early 2009 [9]. This rapid deployment has involved significant financial transfers from all energy customers to those households who installed PV systems [10], and led to the sudden cancelation of the scheme for new participants little more than a year after the scheme commenced. This unfortunate outcome also focussed attention on how the costs and benefits are distributed 
across electricity industry participants beyond PV households including retailers and DNSPs as well as other electricity customers other than those who have deployed PV. For example, the Independent Pricing and Regulatory Tribunal (IPART) of NSW and the Queensland Competition Authority (QCA) were both tasked with determining a fair and reasonable value of PV sourced electricity exported to the grid and, its impacts on Distribution Network Service Providers (DNSPs) and electricity retailers [2,3].

These FiT impacts have occurred within the context of an immature and, at present, somewhat dysfunctional set of retail market arrangements [11]. These arrangements include significant cross-subsidies across, and within, customer classes for cost-recovery of network infrastructure by the monopoly, economically regulated DNSPs. In particular, tariffs are largely consumption based (primarily Flat rates for residential and small business customers although there is growing interest in transitioning these customers to Time-Of-Use rates) whilst network expenditure is significantly driven by peak network demands. Furthermore, there are only limited tariff differences between customers despite widely divergent network asset requirements between low and high density service areas, and customers with low or high peak demand. Large increases in network expenditure and hence network tariffs have occurred in NSW and a number of other Australian jurisdictions over the past five years, focusing greater public and political attention on the questionable efficiency and equity of current arrangements [12].

Metering and market arrangements for PV have important implications in this regard. Gross PV FiT schemes with a set tariff for all PV generation have generally been funded through a specific levy, and therefore do not impact directly on retailer and DNSP sales, and hence their revenue from consumption based tariffs. Net metering of PV generation, by comparison, sees foregone electricity sales from self-consumption reducing both retailer and DNSP revenues. Of course, so do household changes that reduce household consumption such as the use of more energy efficient appliances. On the expenditure side, a key driver of DNSP costs is the load profile of households and, in particular, their levels of peak demand. In Australia, peak residential demand often occurs in the evening of a working weekday, when air-conditioning (summer) or electrical heating (winter) are in widespread use, yet after PV generation has largely ended for the day. So, it is possible for a net-metered PV system to reduce DNSP revenue whilst not assisting in reducing network peak demand, which under simplified and hence smeared cost recovery tariffs exacerbates financial transfers between $\mathrm{PV}$ and non-PV households.

Finally, and of particular interest for this paper, any significant difference between the retail and net-FiT tariffs poses additional complexities for financial analysis by incentivising consumers with PV systems to either maximise or minimise the level of exported PV from their systems by managing their demand profile. For example, households might choose to defer or bring forward operation of non-time critical loads such as pool pumps or hot water systems. Tariff differences can also influence the value of energy efficiency activities, making them more or less likely to occur. Note that load shifting will not only have revenue impacts on retailers and DNSPs for good or bad, but also potentially on network expenditures depending on whether peak loads are reduced or perhaps even increased.

There is a diverse and growing literature on PV economics that presents cost-benefit assessments with respect to both society as a whole - hence considering externalities such as the environmental harms avoided with PV [13-15] - and private industry stakeholders such as PV owners and their electricity utilities. Most of the latter literature has focussed on assessing the value of PV for owners to evaluate whether commercial arrangements and PV policies in place are encouraging consumers to invest in solar energy [16-24]. Australian work includes [25] and [26]. Falling PV prices have now markedly changed the findings of such analysis and [27] argue that grid parity events will occur throughout the next decade in the majority of electricity market segments in the world.

There has been less work to date on the impacts of PV deployment on other electricity industry participants but this area is receiving greater attention with the recent success of PV [28-30]. At the same time there appear to be a number of other transformations underway in electricity industries at the customer interface going under terms including smart grid [31-33] and the Distribution Edge [34]. These transformations include new technologies such as smart metering and smart appliances, and new business models for greater customer engagement in how they achieve their desired energy service requirements. Of particular relevance to this paper is the growing capability, and potentially interest, for customers to shift the timing of key electrical loads that exhibit some form of energy storage. Examples include hot water systems, space heating and cooling, pool pumps, refrigeration, dish washers and clothes washers.

In previous work, we have assessed the societal value of household PV in Sydney [35] and explored the financial value of such systems for households, their retailers and DNSPs [4]. In this paper we study the financial implications of both residential PV systems and potential demand-side response (DSR) on the financial returns for PV customers, retailers and DNSPs for two net-FiT designs that have been implemented in Australia over recent years. It particularly focuses on how the combination of household PV and financially motivated DSR can improve the benefits of PV deployment for households, yet change, perhaps adversely, the cost and benefits seen by retailers and DNSPs, depending on PV policy and retail market settings.

Our methodology is based on actual half-hourly data of PV generation and household consumption for a sample of some 60 residential PV systems in the Australian city of Sydney, matched with half-hourly wholesale prices in the Australian National Electricity Market. We estimate the change in net income (benefits minus costs) for households with PV, their retailer and their DNSP over a one year period. We assume different possible DSR scenarios and both standard Flat and Time of Use (TOU) retail tariffs in our analysis. Additionally we assess possible changes in network costs resulting from changes in the time of peak household demand given such DSR activities for two specific residential and commercial locations in Sydney.

The remainder of this paper is organized as follows. The methodology used for our study is described in Section 2, and the data and assumptions presented in Section 3. Section 4 presents results, applying our model 
for the Australian State of NSW under different net-FiT designs and retail and commercial tariffs for the sample of 60 houses. Finally, Section 5 presents some conclusions of the study and identifies areas for future work.

\section{METHODOLOGY}

In this section we explain our approach to estimate the annual financial impact of PV net-Fit options and potential DSR for PV customers, their retailers and their DNSPs. First we present our approach to estimate the financial impact as a result of commercial transactions between these participants. We then explain how we assess the economic impact of changes in the distribution network peak demand for DNSPs

\subsection{Commercial Impact of Net-Fits}

Under gross metering arrangements all household PV generation (PVelec) is exported to the grid through a separate meter. Metered household load is therefore not impacted. By comparison, under net metering (NM) arrangements households first consume their PVelec onsite and it is only PVelec in excess of their own consumption that is exported to the grid [36]. Thereby, unlike gross metering where PV customers get paid a FiT for the whole of their PV generation, households with NM may have both an incentive and an opportunity to improve financial returns from their PV system by changing their electricity consumption patterns. This is particularly the case when there is a significant difference between the retail electricity tariff and the FiT paid for PV exports. Any such household DSR has potentially significant additional financial implications for electricity industry participants beyond that of the PV owners themselves.

While PV households under NM experience electricity bill savings and FiT payments for exports, their retailers experience reduced customer revenue because they sell less electricity to PV customers, and lose any margin that they make on these sales. However, in the Australian context they may receive a financial gain because any exported PV generation from their customers is 'assigned' to them in the market clearing process, meaning they avoid buying this electricity from the wholesale electricity market. They are not always required to pay customers for these PV exports and although many do offer a payment, it may not reflect the actual value of the electricity to them. By comparison, DNSPs with consumption based network tariffs lose revenue due to PV self consumption whilst retailers are still required to pay them network tariffs on any exported PV generation assigned to them. As noted earlier, DNSPs will not necessarily see countervailing reductions in the expenditure required to serve customers with PV. The revenue of both retailers and DNSPs are therefore likely adversely impacted by self consumption of PV generation, with DNSPs more impacted as they don't necessarily see any reduction in costs with these reduced sales. To further add complexity, PV household DSR in response to NM might conceivably reduce peak demand - for example, in residential areas, by bringing forward loads that usually run in the evening peak period so that they increase PV self consumption. Alternatively, DSR to maximise PV exports might see loads that normally run in the middle of the day deferred to the evening, increasing peak demand in residential areas.

We study two net-FiT designs in this paper that have both been implemented in one or more Australian jurisdictions. The first one, called "Net-high-FiT", is a publicly funded payment - passed-through to end-users in their network tariffs - that rewards PV customers for their exports at a high FiT rate of $60 \phi / \mathrm{kWh}$ - over double the current Flat retail tariff ${ }^{1}$. The second design, called "Net-wt" rewards PV exports exactly at the halfhourly wholesale price of electricity and is based on recent proposals in Australia of time-varying net-FiT rates that represent the wholesale costs of electricity [37]. In the second case, we assume that retailers don't avoid wholesale market costs since they pay the FiT at the actual wholesale price. However we note that in NSW for example such payments are currently voluntary and based on a benchmark value of exports for retailers of 7.7 $\phi / \mathrm{kWh}$ set in [38].

In our model, at half-hour $t$, the self-consumed PV generation $\mathrm{SCt}$ is valued at the actual retail tariff $\mathrm{Rt}$ whereas PV exports Expt are paid at the high feed-in tariff FiT under Net-high-FiT, and at the wholesale price wt under Net-wt; paid by all end-users, and by PV customer retailers respectively. The retailers experience less sales of electricity for the SC under both net-FiT designs. While they no longer sell SC at the retail tariff, they do save the costs of purchasing this electricity in the wholesale market, network charges $\mathrm{Nt}$ and green surcharges g related to the Australian Renewable Energy Target and other environmentally focussed policy measures. Also under Net-high-FiT retailers are 'assigned' their PV customers exports at the wholesale price. For this study we assume that retailers do not voluntarily pay the $\mathrm{PV}$ household for this 'assigned' $\mathrm{PV}$ export. As noted earlier, some do but others don't depending on the particular State jurisdiction, and retailer policy. Note that the financial implications of PV for retailers are particularly challenging to determine given the limited information available on underlying retailing costs. As just one example, all retailers will hold a range of derivative contracts to hedge against future spot price risks. These contracts are confidential, yet can potentially greatly influence financial outcomes associated with avoiding, or changing the timing of wholesale electricity purchases. Our findings for their financial flows must therefore be considered with particular caution.

Finally DNSPs experience a reduction of revenues for all SC which is valued at the distribution network consumption charge $(\mathrm{A} \$ / \mathrm{kWh})$, known as the 'Distribution Use of Systems' DUOSt. Table 1 summarises the equations that describe these commercial arrangements. Note that the retail tariffs may be Flat or Time-of-Use within this formulation. Furthermore, and as discussed in Section 3, DSR by households with PV can change the amount of PV generation that is selfconsumed, and that which is exported, changing these financial outcomes for themselves as well as their retailer and DNSP.

\footnotetext{
1 Note that we use Australian dollars for all financial assessments. While the exchange rate

with other major currencies has varied significantly over recent years, the Australian dollar

has been, on average, at a rough parity with the US dollar over
} this time. 
Table 1. Equations for estimating the change in benefits and costs for PV customers, their retailers and their DNSPs under the two net-FiT scenarios

\begin{tabular}{lll}
\hline Financial Impact on & Under Net-high-FiT & Under Net-wt \\
\hline PV customers & $R_{t} \times S C_{t}+$ FiT $x \operatorname{Exp}_{t}$ & $R_{t} \times S C_{t}+w_{t} \times \operatorname{Exp}_{t}$ \\
\hline Retailers & $\left(-R_{t}+N_{t}+g+w_{t}\right) \times S C_{t}+w_{t} \times \operatorname{Exp}_{t}$ & $\left(-R_{t}+N_{t}+g+w_{t}\right) \times S C_{t}$ \\
\hline DNSPs & $D U O S_{t} \times S C_{t}$ & \\
\hline
\end{tabular}

\subsection{Economic Impact of Changes in the Network Peak} Demand

Appropriately located PV systems in the grid may defer or avoid the augmentation of transmission and distribution infrastructure, offering potential significant economic value [39]. The key challenge is to estimate how much PV, in which locations and at what times, and with what expected operational characteristics might be able to contribute to avoided network expenditure through reduction in peak loads. Similarly DSR can also potentially offer network deferral value, yet might also contribute to increasing network peak demand and bringing forward augmentation investment if inappropriate price signals are in place with PV.

Assessing the value of deferral or the bringing forward of network augmentation is extremely complex. Simplified approaches are available such as that of [14], where the reduction in transmission constraints, reflected in the California nodal prices, is used to establish a network value for PVelec. [40] estimated network values for particular locations in the South West Interconnected System (SWIS) of Western Australia based on an assumed indicative deferral investment cost. [35] proposed an alternative to these approaches using estimated savings from deferral of particular planned network investments in Sydney that are provided by the relevant DNSPs. Such deferrals are intended to be triggered by successful DNSP contracts with parties that can offer assured demand reductions or additional generation in that location at the expected time and season of peak demand. As such, and despite the current absence of an effective regulatory framework that appropriately facilitates and motivates DNSPs to make such payments [37], we use this approach to estimate the potential benefits and costs of changes in the peak demand due to PV generation and DSR within a net-FiT policy context. Note that PV will have no network deferral value in locations where the peak occurs outside daylight hours, and maximum network deferral value where the network peak demand occurs at around midday in summer under 'clear sky' weather conditions.

We consider the impact of both PVelec and DSR on the peak demand of the distribution network. To do that we first estimate the change, in $\mathrm{kW}$, in the annual peak load triggered by PVelec, $\Delta$ peakpv and by any PV customers DSR, $\Delta$ peakdsr. We then multiply such change in peak demand by its value for DNSPs in that particular location, $\mathrm{S}$, in $\mathrm{A} \$ / \mathrm{kW}$. As such, in the light of such impacts, the overall economic impact of household PV and DSR on DNSPs is as in Eq. 1.

Financial Impact on DNSPs $=$ DUOSt $\mathrm{x} S \mathrm{St}+\mathrm{S} \mathrm{x}$ $(\Delta$ peakpv $+\Delta$ peakdsr $)$

We note that the network value or cost of household PV and DSR is very location-specific and values obtained in this paper don't represent the general case in Sydney. However, there are some areas of the distribution network under constraint and that therefore potentially require augmentation and thus, for illustrative purposes, we have undertaken an assessment for two such specific locations. There is also growing discussion regarding the potential network challenges associated with PV exports into the network. These are associated with a range of technical issues [41] and have seen some policy efforts to encourage households to increase their levels of self consumption of PV generation [7]. We do not attempt to model the potential benefits of self consumption in this regard, but discuss its implications in light of our results in the paper's Conclusion.

\section{DATA AND ASSUMPTIONS}

\subsection{PV and NEM Data}

To carry out these estimations we use actual halfhourly household electricity consumption and PV generation data for a one year period FY2010 ${ }^{2}$ obtained from 61 households in Sydney that each have PV systems of around $1 \mathrm{~kW}$ capacity ${ }^{3}$. Much of the existing financial analysis of PV uses measured or modelled performance of single systems. In practice, residential systems will often vary significantly in performance due to varying equipment quality, system orientation and tilt, and nonideal solar access. Furthermore, household electricity consumption varies very markedly in both magnitude and profile depending on factors including house type, chosen appliances, the number of household occupants and their behaviour. Our approach therefore uses load and PV data from a significant number of households in order to provide more realistic estimates of PV generation and financial impacts. The average annual PV production of these houses over the year was $1,200 \mathrm{kWh} / \mathrm{kW} /$ year. This value is actually slightly lower than the average 1,282 $\mathrm{kWh} / \mathrm{kW} /$ year for $1 \mathrm{~kW}$ PV systems during FY2011 in the Ausgrid distribution area of Sydney according to [36]. We do see some significant year to year variation of total solar insolation, however, there may also be some adverse factors for the systems used in this study, as they were all installed as part of a single government program. As such, our results may under-estimate the typical value of financial flows associated with residential PV systems in Sydney.

To work with a more representative sample of systems in Sydney we escalated the PV generation to be equivalent to a $2.6 \mathrm{~kW}$ system - the current average PV system size in NSW [42]. The average annual consumption of these houses is $7,100 \mathrm{kWh} /$ year and

\footnotetext{
${ }^{2}$ FY indicates the Australian financial year which starts on the 1 st of July of the previous shown year and finishes on the 30th of June of the shown year.

3 These residential PV systems were installed in the Western Sydney suburb of Blacktown, within the distribution network of Endeavour Energy, as part of the Australian Solar Cities program.
} 
therefore, considering a $2.6 \mathrm{~kW}$ average sample, the average level of export of these households is about a $50 \%$ of the total PV generation.

Furthermore we use actual FY2010 half-hourly wholesale electricity prices for the NSW region of the NEM over the study period. This dataset appears reasonably representative of the long term average wholesale price in NSW to date. The average NSW wholesale price during FY2010 was A $\$ 44 / \mathrm{MWh}$ while the average NSW wholesale price of the last 7 years is A \$46/MWh [43]. However, note that averaged wholesale prices in the NEM can be greatly influenced by a small number of hours of extremely high price events so, again caution is required when interpreting our results. These price spikes are generally seen at times of higher demand but are often driven by highly infrequent and uncertain extreme weather conditions and system contingencies such as equipment failure. The timing and impact of such price spikes can greatly influence financial analysis such as undertaken in this paper based on wholesale spot prices. Hence, we truncate all extreme high prices to a maximum of $\mathrm{A} \$ 500 / \mathrm{MWh}$ - a price that is still approximately ten times the average wholesale price.

These prices were escalated to FY2013 prices using the projections of [44] under its so-called 'Clean Energy Future' scenario which incorporates current Australian clean energy policies such as the Australian carbon price. These prices were also adjusted by the corresponding marginal loss factor and distribution loss factor of the location of these PV systems; $0.53 \%$ and $7.7 \%$ respectively [45, 46]. This approach captures the correlation between PVelec and wholesale electricity market prices which has considerable relevance to financial flows for PV customers and retailers under some scenarios.

\subsection{Model Assumptions}

Most NSW households still have conventional disctype accumulation meters and while installation of a PV system generally requires that an interval meter be installed, current retail contract arrangements still typically permit customers to be on Flat or inclining block tariffs - that is, a fixed $\$ / \mathrm{kWh}$ charge for all, or a given portion of consumption between meter readings typically done every two to three months. Network tariffs can also be Flat or TOU according to the particular household metering and retail contract. Therefore, private commercial cash flows between market participants were estimated using regulated FY2013 Flat and Time of Use (TOU) Endeavour Energy network charges and Origin Energy ${ }^{4}$ retail electricity tariffs for residential customers in Sydney [47, 48] $]^{5}$. Note that residential customers contract only with the retailer who, in turn, pay the network tariff to the DNSP. The chosen tariffs are shown in Table 2.

The network tariffs presented in Table 2 include not only distribution use of system charges (DUOS) yet also transmission costs and pass-through cost-recovery components related to the NSW Climate Change Fund

\footnotetext{
${ }^{4}$ Origin Energy is the Australia's largest retailer with a very significant NSW presence.

5 NSW does have a so-called competitive retail market, and a wide variety of retail tariff offers at the residential level. However, the chosen default regulated tariffs still apply for those customers who have not taken up a competitive offering and appear to be generally representative for NSW under current arrangements.
}

which actually pays for the SBS. According to [49] DUOS charges correspond to $87 \%$ of the total average network bill - based on an average annual consumption of $6,000 \mathrm{kWh}$ - for residential customers located in its distribution area. This contribution includes both fixed and variable DUOS charges. Therefore, assuming that the variable charge of a network bill represents around $85 \%$ of a total annual bill - for a $6,000 \mathrm{kWh} /$ year customer with the tariffs provided Table 2 , yet also including fixed charges - we apply the same proportion for DUOS. As such, the resulting variable DUOS corresponds to $74 \%$ of the total network bill and hence we apply this percentage to each component of the network tariff of Table 2 to obtain variable DUOS charges in $\phi / \mathrm{kWh}$.

The cost components that contribute to the final retail electricity tariffs can be complex and difficult to estimate as is, therefore, the profit margin for retailers. In estimating the revenue impacts of PV for retailers, we use the regulated network tariffs but also a reference value of $\mathrm{g}$ of $1.15 \mathrm{\phi} / \mathrm{kWh}$ obtained from the retailer cost component breakdown provided as part of the regulatory determination of regulated retail prices for FY2013 [50].

As noted earlier we consider two FiT scenarios for residential customers with PV systems; a high net-FiT PV export rate of $60 \phi / \mathrm{kWh}$ which is more than double the $26.7 \phi / \mathrm{kWh}$ retail tariff, and an export rate at the FY2013 wholesale electricity price whose average is well under a third of the retail tariff. We use a simple model of potential DSR by PV households to explore its potential impacts under these net-FiT scenarios. In practice, of course the readiness, willingness and ability of these households to shift load will be highly context specific. Furthermore, the most valuable DSR will depend on the particular house's current PV generation and load profiles over the year. Such complexities are beyond this study.

In the case of Net-high-FiT we shift uniformly a percentage of each household load from the time window $10 \mathrm{am}-2 \mathrm{pm}$ when PV output is generally greatest, to the window $5 \mathrm{pm}-9 \mathrm{pm}$ when PV output is effectively finished for the day, hence increasing PV exports. For Net-wt we shift load from the window $5 \mathrm{pm}-9 \mathrm{pm}$ to $10 \mathrm{am}-2 \mathrm{pm}$ to maximise self-consumption. We calculated a fixed proportion of every half-hourly load of the four hours period, we subtracted them from the original load, we sum them and later distributed equally to every halfhourly load of the other four hours period. We consider percentage of load shifting of $10 \%, 30 \%$ and $50 \%$. Thereby if L10am-2pm t and L5pm-9pm $t$ are the household loads at a half-hour $t$ during midday hours and evening and $\% \mathrm{P}$ is the percentage of load shifting while final and initial refer to the states of after and before shifting respectively; then Eq. 2 and 3 illustrate the calculation of the resulting loads in half-hours $t^{*}$ and $t^{* *}$ after applying DSR for the case of maximizing exports. Table 3 shows the annual effect of these DSR scenarios on our household data and the new level of exports. The yearly values are averaged over a year of data and over all households systems. Note that this load shifting is relatively modest by comparison with what might be seen in a household that has the flexibility to move major loads across these periods. Fig. 1 illustrates how DSR changes the average load profile of the winter month of July to increase PV exports. 
Table 2. The NSW Residential Retail Tariffs and Network Charges for FY2013 used in this study.

\begin{tabular}{|c|c|c|c|}
\hline Type of Tariff & Tariff Component & $\begin{array}{c}\text { Retail } \\
\text { Tariff }[\boldsymbol{c} / \boldsymbol{k} \boldsymbol{W h}]\end{array}$ & $\begin{array}{c}\text { Network } \\
\text { Tariff Component } \\
{[\mathrm{c} / \mathrm{kWh}]}\end{array}$ \\
\hline \multicolumn{4}{|c|}{ Flat tariffs } \\
\hline & Consumption of first $1,750 \mathrm{kWh} /$ quarterly: & 26.7 & 11.9 \\
\hline & Remaining consumption kWh/quarterly: & 29.8 & 16.0 \\
\hline \multicolumn{4}{|c|}{ TOU tariffs } \\
\hline & Peak consumption (1pm - 8pm on business days): & 38.9 & 21.3 \\
\hline & $\begin{array}{l}\text { Shoulder consumption ( } 7 \mathrm{am}-1 \mathrm{pm} \text { and } 8 \mathrm{pm}-10 \mathrm{pm} \\
\text { business days): }\end{array}$ & 29.8 & 12.3 \\
\hline & Off peak consumption - (10pm-7am everyday) & 15.0 & 5.2 \\
\hline
\end{tabular}

Table 3. Effect of the three DSR levels on household loads for both the case of maximising PV exports and maximising self consumption.

\begin{tabular}{lcccc}
\hline \multicolumn{1}{c}{ DSR scenario } & $\begin{array}{c}\text { Annual shifted } \\
\text { load } \\
{[\mathrm{kWh} / \text { year] }}\end{array}$ & $\begin{array}{c}\text { Annual shifted load } \\
\text { as \% of total load }\end{array}$ & $\begin{array}{c}\text { Annual PV } \\
\text { exports } \\
{[\mathrm{kWh} / \text { year] }}\end{array}$ & $\begin{array}{c}\text { Annual PV exports as \% } \\
\text { of total PV generation }\end{array}$ \\
\hline No load shifting & 0 & 0 & 1,537 & $49 \%$ \\
\hline $10 \%$ - maximizing exports & 122 & $2 \%$ & 1,586 & $51 \%$ \\
\hline $30 \%$ - maximizing exports & 365 & $5 \%$ & 1,695 & $54 \%$ \\
\hline $50 \%$ - maximizing exports & 609 & $9 \%$ & 1,825 & $58 \%$ \\
\hline $10 \%$ - maximizing SC & 175 & $2 \%$ & 1,433 & $46 \%$ \\
\hline $30 \%$ - maximizing SC & 525 & $7 \%$ & 1,258 & $40 \%$ \\
\hline $50 \%$ - maximizing SC & 875 & $12 \%$ & 1,123 & $36 \%$ \\
\hline
\end{tabular}

$$
\begin{aligned}
& L_{10 a m-2 p m t^{*} \text { final }}=L_{10 a m-2 p m t^{*} \text { initial }} \times(1-\% P) \\
& L_{5 p m-9 p m t^{* *} \text { final }}=L_{5 p m-9 p m t^{* *} \text { initial }}+\frac{1}{(2 \times 4)} \sum_{t=10 a m}^{2 p m} \% P \times L_{10 a m-2 p m t \text { initial }}
\end{aligned}
$$

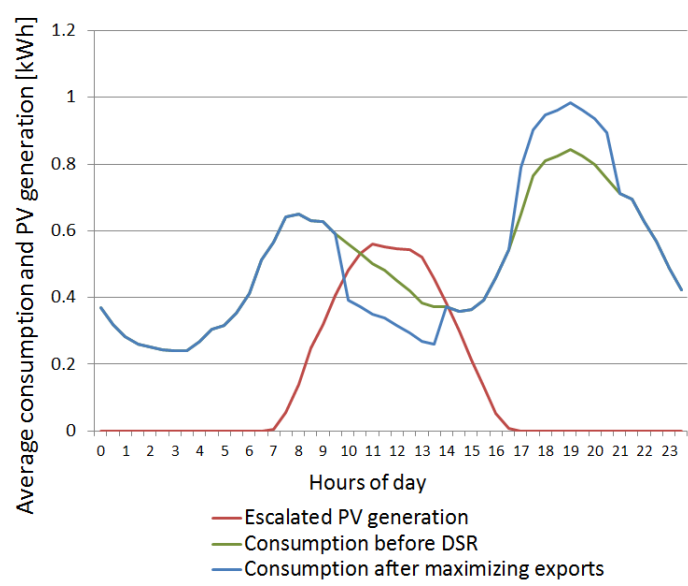

Fig. 1. Average household PV generation and load profiles of July 2009 showing how 30\% DSR to increase PV exports changes the average household demand profile by reducing midday load and increasing peak evening load.

Also to estimate the change in the distribution network peak demand caused by both PVelec and potential DSR we also consider the case where the PV systems are located in two specific areas in the Sydney distribution network that have network capacity constraints. The first location is Rooty Hill, which is in fact the area where these PV systems are located. The area has a mixed commercial and residential load profile. The second network area, Warringah, is a predominantly residential area with, therefore, a rather different load profile. In particular, its peak demand occurs in summer in the evening, rather than in the afternoon as seen in Rooty Hill. For both we estimate the change in the network peak demand using average PV generation and consumption data of the month where the actual annual peaks occur. The value of such change for DNSPs in $\mathrm{A} \$ / \mathrm{kW}$ was obtained from demand managements studies undertaken by the two DNSPs involved [51, 52]. The Rooty Hill potential PV network deferral value is A $\$ 204 / \mathrm{kW}$ based on a two year deferral of the new North Glendenning Substation whose cost is estimated at A $\$ 23 \mathrm{~m}$. Warringah's potential PV network deferral value is A $\$ 668 / \mathrm{kW}$ based on a one year deferral of a new $132 / 33 \mathrm{kV}$ substation which would save around $\mathrm{A} \$ 1.8 \mathrm{~m}$. We note that DSR value is very location-specific and these estimations should be considered as an example and not the general case in Sydney. [35] shows estimated values for different locations in Sydney which range from $\mathrm{A} \$ 100$ to $\mathrm{A} \$ 800 / \mathrm{kW}$ for areas facing future constraints. The potential value of PV to defer network augmentation is, of course, zero if located in areas of the network with ample capacity for current and projected future demand growth, or if peak demand occurs outside daylight hours. By contrast, and as we shall demonstrate, DSR to maximise or minimise PV export may well see significant household load changes at time of evening 
peak demand outside daylight hours with the effect of either increasing or reducing such peaks.

\section{FINANCIAL IMPACT OF PV AND DSR ON HOUSEHOLDS, RETAILERS AND DNSPS}

In this section we present results on the value (financial benefits minus costs) of these two net-FiT designs for households with PV, their retailers and their DNSPs under a range of potential DSR efforts. These values are calculated for the single year FY2013 in A $\$$ household/year.

\subsection{Household PV Value}

The performance of domestic rooftop systems in Sydney has proven to vary significantly according to the location and quality of installation including issues of system orientation and shading [53].

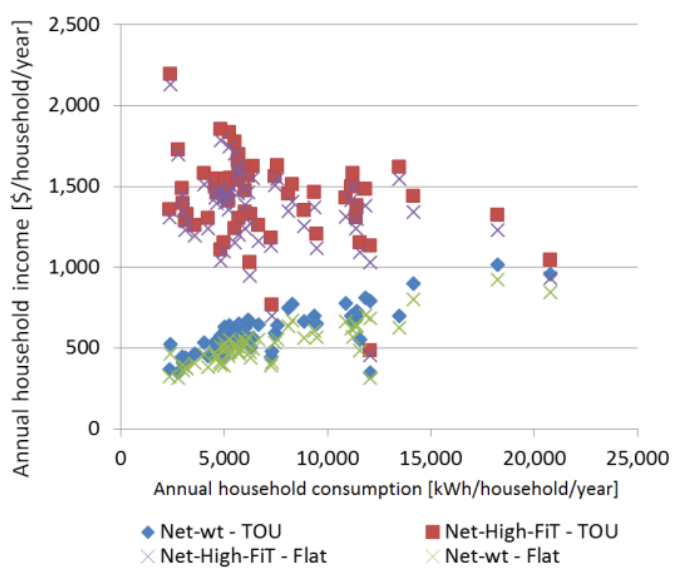

Fig. 2. Annual PV system revenue and electricity consumption of 61 households in Sydney with PV systems of $2.6 \mathrm{~kW}$ under Net-high-FiT and Net-wt arrangements.
Fig. 2 presents a scatter plot of the spread of PV revenues against annual load for each house under the four Net-FiT and retail tariff scenarios, and emphasizes the great diversity in household demand, and PV system performance across the 61 sample households. PV, unsurprisingly, is of greater value to households under Net-high-FiT than Net-wt. given that difference in the tariffs for PV exports is $60 \notin / \mathrm{kWh}$ versus a calculated average wholesale value of PV exports in FY2013 of $6 \notin / \mathrm{kWh}$. The value difference is less than this, however, because around $50 \%$ of PV generation is self-consumed, and hence paid at the same rate under both FiT scenarios. Households with higher levels of consumption generally experience higher value under Net-wt and lower returns under Net-high-FiT because the higher the household consumption, the lower the levels of PV exports. The household load profile over the day can, however, also significantly change these levels of export. Furthermore, it is also evident that TOU retail tariff arrangements offer higher PV value for households than Flat tariffs since hours of high solar PV generation match well with the shoulder and peak TOU rates, hence offering higher savings in the electricity bill from PV self-consumption.

4.1 Household, Retailer and DNSP Revenue Impacts with PV and DSR

The resulting average value impacts of the $2.6 \mathrm{~kW}$ household PV systems and customer DSR on households $(\mathrm{H})$, their retailers $(\mathrm{R})$ and their DNSPs (D) is shown in Fig. 3 for three levels of DSR under the two net-FiT scenarios and both Flat and TOU retail tariffs. Table 4 describes the scenarios used in this analysis.

Table 4. PV FiT Policy and DSR scenarios

\begin{tabular}{ll}
\hline $\begin{array}{l}\text { PV policy and DSR } \\
\text { scenarios }\end{array}$ & Description \\
\hline FiT-0\% $0 \%$ & Customers under Net-high-FiT without any DSR \\
\hline FiT-10\% & Customers under Net-high-FiT shifting 10\% of load to the evening to maximize exports \\
\hline FiT-30\% & Customers under Net-high-FiT shifting 30\% of load to the evening to maximize exports \\
\hline FiT-50\% & Customers under Net-high-FiT shifting $50 \%$ of load to the evening to maximize exports \\
\hline$w t-0 \%$ & Customers under Net-wt without any DSR \\
\hline$w t-10 \%$ & Customers under Net- wt shifting $10 \%$ of load to the middle of the day to maximize SC \\
\hline$w t-30 \%$ & Customers under Net- wt shifting $30 \%$ of load to the middle of the day to maximize SC \\
\hline$w t-50 \%$ & Customers under Net- wt shifting $50 \%$ of load to the middle of the day to maximize SC \\
\hline
\end{tabular}




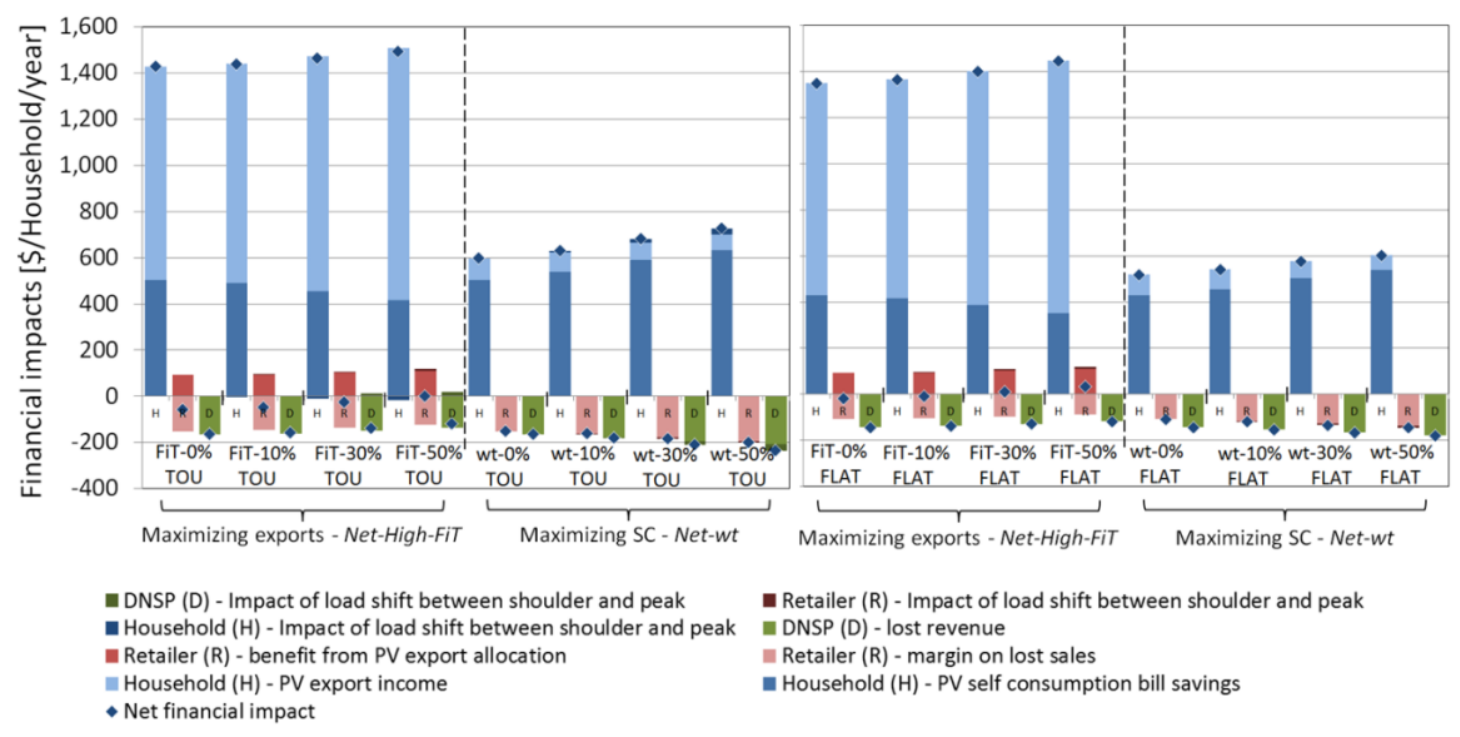

Fig. 3. Estimated average financial impact of household PV on the system owners, their retailers and their DNSPs for both the high and low net-FiT tariffs, and either TOU or Flat retail tariffs.

Fig. 3 highlights that the value of PV for a household is more than double when receiving the higher net-FiT tariff. Furthermore, and as noted above, TOU tariffs offer greater value for households than Flat tariffs. DSR offers a relatively modest increase in revenue under Net-highFiT but a considerably greater percentage improvement under Net-wt. Under TOU tariffs, the value of DSR under the Net-high-FiT is somewhat negated by the impact of moving load from the shoulder tariff period to the peak tariff period for working weekdays. Conversely, DSR provides greater household benefits under Net-wt with TOU tariffs as load is moved from the peak tariff period to the shoulder period. Note, however, that households under TOU tariffs pay these rates for all of their remaining electricity consumption and the financial impacts of this will depend on the general load profile of the household. This should, of course, also be a consideration when households contemplate what type of retail contract might be most financially attractive.

Also of relevance to these findings is that the levels of DSR we modelled may well be conservative given that some households may be able to move loads that represent more than $50 \%$ of their loads in the middle of the day, or evening, if the financial incentives are sufficient. The impact of PV on retailers is complex and, as noted previously, difficult to assess. In particular, extreme price events are inherently unpredictable and retailers utilise a range of hedging strategies. Still, given our use of wholesale NEM prices (truncated at a maximum $\$ 500 / \mathrm{MWh}$ ) to represent their energy purchase costs, retailers lose revenue from reduced electricity sales to PV households, but can benefit under Net-high-FiT if they do not pay PV households for the PV exports that are assigned to them. Note that in NSW at present, retailer payments to PV households for exported PV generation are voluntary whilst in other States they are compulsory. Retailers fare worse under TOU tariffs given the match between PV generation and the higher priced shoulder and peak tariffs. Increased PV exports through DSR both reduce the amount of lost electricity sales and increases this PV allocation and might even see retailers benefiting overall from households deploying PV. Under TOU tariffs the retailers may also benefit modestly from having household load moved into the higher peak tariff period. By comparison, retailers are always adversely

impacted under Net-wt given reduced sales, and DSR to increase self consumption furthers these net revenue losses.

The PV household's DNSP experiences a significant reduction in revenue under all scenarios from reduced sales, and hence reduced network tariff income. DSR reduces DNSP revenue losses under Net-high-FiT as they receive their network tariff on exported $\mathrm{PV}$ generation from the retailer who it has been assigned to. By contrast, DSR under Net-wt to increase self-consumption increases DNSP revenue losses. Again, as seen with retailers, revenue losses are worse under TOU tariffs than Flat tariffs. Regulatory arrangements for Australian DNSPs will normally permit them to correct a reduction in revenue without reduction in expenditure through increased electricity network tariffs. As such, this reduction of revenues is likely, in the longer term, to end up as a financial transfer from all electricity end-users to those who install PV.

\subsection{DNSP Expenditure Impacts from PV and DSR}

Beyond the revenue impacts for DNSPs, there is the potential impact of the PV systems and any associated DSR on network expenditure through changes to peak network demand, or through management of increased PV exports. To illustrate the potential overall effect of PV on peak network demand, we consider the expenditure implications of PV deployment in two constrained network regions in Sydney - one which is predominantly residential and the other which has a mix of commercial and residential loads. In Fig. 4 average DNSP revenue losses and impact on network expenditure for the two net-FiT scenarios are shown for the case of Flat residential tariffs. 


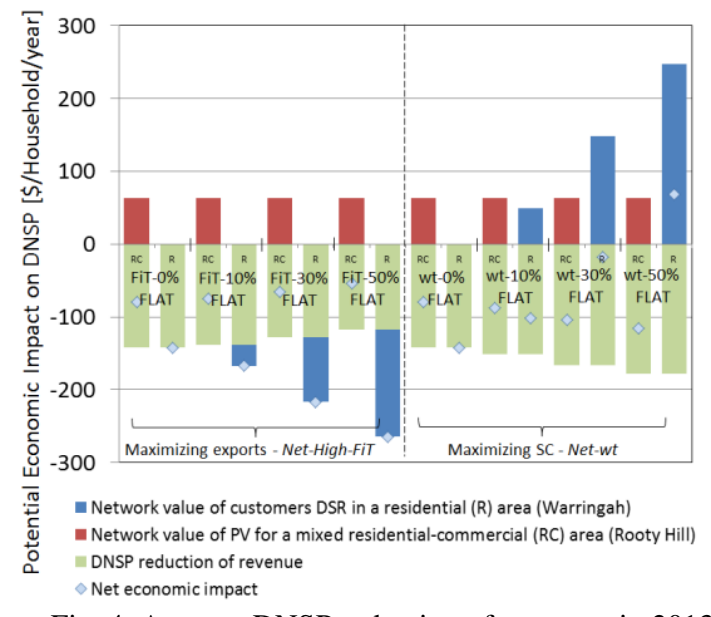

Fig. 4. Average DNSP reduction of revenues in 2013 and potential network value in a residential and commercial constraint area of the distribution network.

It can be seen that PV systems in the mixed commercial-residential region (Rooty Hill) can potentially defer network augmentation and this might, under some circumstances, assist in reducing the overall adverse impact on DNSPs of PV deployment. By comparison, $\mathrm{PV}$ in the predominantly residential area has no deferral value as the time of peak demand is in the evening after PV generation has ended. DSR to increase exports reduces revenue losses but has no network 'expenditure' value in the mixed residential-commercial region, and potentially has marked adverse 'expenditure' impacts in the predominantly residential area by moving midday loads onto the existing evening peak.
By comparison, while DSR to increase self consumption worsens revenue losses for the DNSP, it has no expenditure implications for the mixed residentialcommercial region yet might potentially reduce required network expenditures in constrained residential areas. Fig. 4 shows that the network value, unlike commercial cash flows, varies considerably with these customers demand side response. Hence, in the residential area of Warringah maximizing exports could be detrimental for network expenditure while maximizing self-consumption could be beneficial potentially offering even a positive overall network value to DNSPs under the 50\% DSR scenario. As noted earlier, however, such network value is very location-specific and results of Fig. 4 should be considered just as an example of specific locations under network constraints in the city of Sydney. They don't represent the general case for either residential or commercial areas. Most PV in Australia is going into regions that don't offer deferral value at present, yet with the right price signals PV and DSR could add potential considerable value. Furthermore, it is important to note that these deferral values do not apply year after year but are, instead, calculated on a one-off upfront basis. As such, their impact is generally far less significant than the annual revenue impacts. Finally, there are potential implications of increased PV exports to also potentially require network expenditure to manage issues such as voltage rise and reverse power flows through network equipment intended for uni-directional operation.

Finally to highlight the differences across the 60 sample households we show in Fig. 5 a plot of the net benefit/cost for each PV household, their retailer and their DNSPs under Flat electricity tariffs.
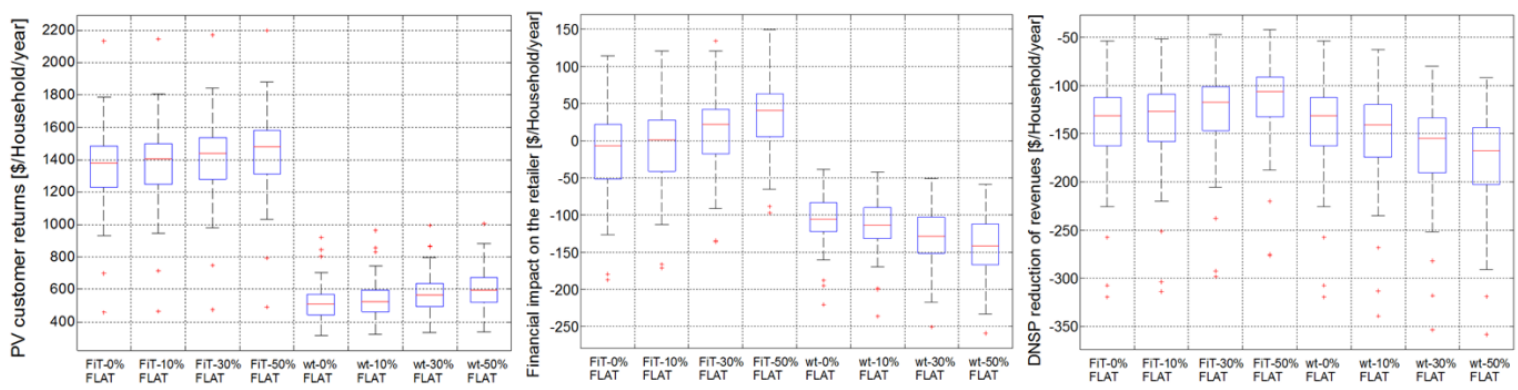

Fig. 5. Box plot of the net benefit/cost for PV households, retailers and DNSPs. Box plots identify the median, the 25th and 75 th percentiles of system value while whiskers extend to the most extreme data points not considered outliers, and outliers are plotted individually.

These highlight again the great variation seen between households in terms of their own PV value, and also the implications for their retailers and DNSPs. As noted earlier, key factors include the quality of the PV installation in terms of orientation and shading, and the typical household load profile This variability highlights the potential difficulties of generalising regarding value outcomes for participants from a so-called average PV installation.

Similar variability arises in the potential network deferral value of PV. Fig. 6 presents a box plot of the economic impacts of our 60 households sample due to potential changes in the distribution network peak demand -including DNSP reduction of revenues - with customers DSR and PV in Sydney for areas under network constraints. We again note that there is no either PV value for the residential area of Warringah nor customer DSR value for the commercial area of Rooty Hill and they therefore aren't included in the figure. 


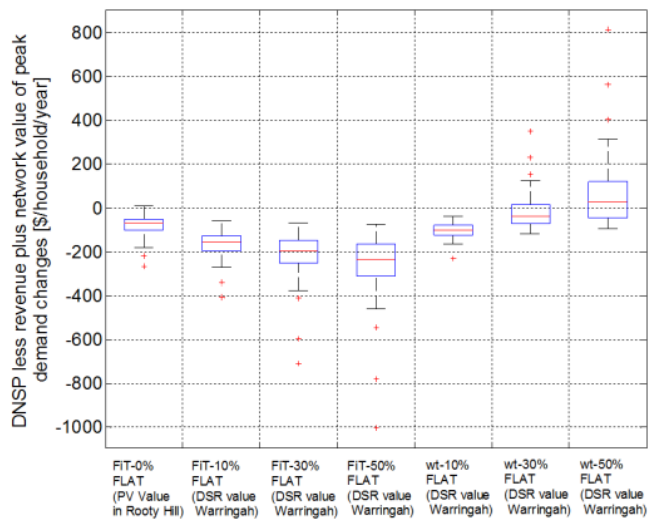

Fig. 6. Potential impact of net-FiT policies on DNSPs network expenditure in the residential area of Warringah and the commercial area of Rooty Hill for different DSR scenarios. Box plots identify the median, the 25 th and 75th percentiles of system value while whiskers extend to the most extreme data points not considered outliers, and outliers are plotted individually.

Again, this highlights the potential difficulties of ascribing a network value on the basis of an average PV system.

\section{CONCLUSIONS}

Household PV deployment has significant costbenefit implications for not only the PV households but also other industry participants, notably their retailers and DNSPs. These implications are very influenced by the nature of PV support policies, and wider retail market arrangements. Furthermore, they can also be impacted by other actions undertaken by PV households to modify their load profile in order to increase PV exports or self consumption. Net-FiT PV policies have been deployed in a number of jurisdictions around the world and, unlike gross FiT policies, change the overall household load supplied (and billed) by retailers and DNSPs with adverse revenue implications for these participants. Policy arrangements such as whether and how exported PV generation is assigned to retailers and DNSPs can, by contrast, have positive revenue implications for retailers and DNSPs. The use of TOU versus Flat consumption tariffs also impacts on revenues - in the NSW case certainly, TOU tariffs improve PV household outcomes but worsen retailer and DNSP outcomes.

Household DSR to improve revenue from their PV system adds further complexities. The relatively simple and conservative DSR modelled in this study had relatively modest impacts on household revenue, varying between $5 \%$ and $22 \%$ for the $50 \%$ DSR case under Nethigh-FiT and Net-wt respectively.

The impacts of DSR on retailer and DNSP revenues were, by contrast more marked in percentage terms. Under a high net-FiT tariff, actions to increase PV exports reduced retailer and DNSP revenue losses through reduced 'lost' sales and hence greater consumption based tariff earnings. In NSW retailers can also benefit in having the PV export generation assigned to them. By contrast, a net-FiT tariff below retail tariffs, driving DSR actions to increase self-consumption can worsen retailer and DNSP revenue losses significantly.

In terms of DNSP expenditures, PV in constrained regions of the network may improve or have no impact on peak network demand (and hence the trigger for network augmentation expenditure) depending on its match with the season and time of these peaks. DSR in these constrained regions may worsen these peaks if moving load from the middle of the day into the evening in order to increase PV exports. Alternatively, DSR to improve self consumption might reduce evening peaks and therefore offer additional network value.

The findings of our study highlight the importance of considering PV support policy implications beyond their expected impacts on households considering purchasing a PV system, to their potential impacts on retailers and, particularly given that they are generally regulated monopoly service providers, the DNSPs. Retailers seem likely to be generally adversely impacted by their customers deploying PV although it should be noted that this is a similar situation in many regards to having their customers deploy energy efficient appliances or otherwise change their behaviour to reduce consumption. The potential tensions for DNSPs are apparent in NSW. PV systems may significantly reduce their revenue without reducing network expenditure. With regard to household DSR, they suffer less revenue loss under higher PV exports but this may worsen evening peak demands. By comparison, greater self-consumption of PV generation by households might reduce evening peak demand but also worsens DNSP revenue impacts. Although we don't attempt to model it, greater selfconsumption is also potentially valuable in avoiding DNSP expenditures to manage greater PV exports into the distribution network.

In the end, DNSPs as regulated monopoly providers will generally be permitted to charge network tariffs sufficient to cover prudent expenditure and provide a suitable margin. Reduced revenues from one class of customers without associated reduced costs will therefore involve cross-subsidies. Of course, in almost all electricity industry jurisdictions, network tariffs already involve significant cross-subsidies within and between different customer classes. And while the deployment of $\mathrm{PV}$ can drive increased financial transfers between nonPV and PV households, these are not issues for PV alone. Household energy efficiency also reduces DNSP revenue flows and won't necessarily reduce peak demands, whilst households with large air-conditioning loads in Australia receive a potentially very significant cross subsidy from households without them [54]. However, growing levels of PV deployment will require greater attention to such financial transfers. DSR adds to the potential complexities and will also increasingly need to be considered as the opportunities and motivation to undertake DSR to improve the value of household PV continues to grow.

The potential for PV and DSR to increase or reduce network expenditure is a promising but particularly complex issue. Many jurisdictional arrangements including those in Australia still do not provide an appropriate framework for non-network options to receive the potential network value that they can bring [12]. There is important progress to be made in such arrangements including, perhaps, creating a greater role for Energy Service Providers who can aggregate a range of activities including energy efficiency, distributed generation including PV and DSR to maximise both its energy market as well as network value. Efforts in this regard are growing in Australia [37] and elsewhere. In 
this way, the future of PV policy is increasingly one of addressing the currently inadequate regulatory and policy settings for electricity retail markets.

\section{REFERENCES}

1. REN21, Renewables 2013 - Global Status Report, 2013, Renewable Energy Policy Network for the 21st Century: Paris.

2. IPART, Solar feed-in tariffs - Setting a fair and reasonable value for electricity generated by smallscale solar PV units in NSW, 2012, Independent Pricing and Regulatory Tribunal: Final Report, prepared for the NSW government, Sydney.

3. QCA, Estimating a Fair and Reasonable Solar Feedin Tariff for Queensland, 2012, Queensland Competition Authority: Issues Paper, Brisbane, Australia.

4. Oliva, S.J. and I.F. MacGill. Assessing the impact of household PV systems on the profits of all electricity industry participants. in Power and Energy Society General Meeting, 2012 IEEE. 2012.

5. DECC, Feed-in Tariffs Scheme - Government Response to Consultation on Comprehensive Review Phase 1 - Tariffs for solar PV, 2012, Department of Energy \& Climate Change: London, UK.

6. Polo, A.L. and R. Haas, An international overview of promotion policies for grid-connected photovoltaic systems. Progress in Photovoltaics: Research and Applications, 2012: p. n/a-n/a.

7. Solangi, K.H., et al., A review on global solar energy policy. Renewable and Sustainable Energy Reviews, 2011. 15(4): p. 2149-2163.

8. Avril, S., C. Mansilla, and T. Lemaire, Solar energy support in the Asia-Pacific region. Progress in Photovoltaics: Research and Applications, 2012. 20(6): p. 785-800.

9. NSW Government, NSW Solar Feed-in Tariff Report to Ministers, 2009.

10. NSW Auditor-General, Special Report: Solar Bonus Scheme, 2011: Prepared to Parliament - Financial Audits, Sydney.

11. Outhred, H. and I. MacGill, Electricity Industry Restructuring for Efficiency and Sustainability Lessons from the Australian Experience. 2006 ACEEE Summer Study on Energy Efficiency in Buildings, Asilomar, 2006.

12. Productivity Commission, Electricity Network Regulatory Frameworks. Draft Report, Canberra, 2012.

13. Haas, R., The value of photovoltaic electricity for society. Solar Energy, 1995. 54(1): p. 25-31.

14. Borenstein, S., The Market Value and Cost of Solar Photovoltaic Electricity Production. Centre for the Study of Energy Markets, University of California, WP 176, 2008.

15. Borenstein, S., The Private and Public Economies of Renewable Electricity Generation. The Journal of Economic Perspectives, 2012. 26(1): p. 67-92.

16. Borenstein, S., Electricity Rate Structures and the Economics of Solar PV: Could Mandatory Time-ofUse Rates Undermine California's Solar Photovoltaic Subsidies? Center for the Study of Energy Markets, University of California Energy Institute, WP 172, 2007.

17. Mills, A., et al., The impact of retail rate structures on the economics of commercial photovoltaic systems in California. Energy Policy, 2008. 36(9): p. 3266-3277.

18. Darghouth, N., G.L. Barbose, and R.H. Wiser, Electricity Bill Savings from Residential Photovoltaic Systems: Sensitivities to Changes in Future Electricity Market Conditions, 2013, Ernest Orlando Lawrence Berkeley National Laboratory, Environmental Energy Technologies Division.

19. Darghouth, N.R., G. Barbose, and R. Wiser, The impact of rate design and net metering on the bill savings from distributed PV for residential customers in California. Energy Policy, 2011. 39(9): p. 52435253.

20. Algora, C., A grid-connected home PV installation in Madrid: the user's perspective. Progress in Photovoltaics: Research and Applications, 2006. 14(3): p. 261-273.

21. Colmenar-Santos, A., et al., Profitability analysis of grid-connected photovoltaic facilities for household electricity self-sufficiency. Energy Policy, 2012. 51(0): p. 749-764.

22. Muhammad-Sukki, F., et al., An evaluation of the installation of solar photovoltaic in residential houses in Malaysia: Past, present, and future. Energy Policy, 2011. 39(12): p. 7975-7987.

23. Martinez-Cesena, E.A., B. Azzopardi, and J. Mutale, Assessment of domestic photovoltaic systems based on real options theory. Progress in Photovoltaics: Research and Applications, 2013. 21(2): p. 250-262.

24. Nofuentes, G., J. Aguilera, and F.J. Muñoz, Tools for the profitability analysis of grid-connected photovoltaics. Progress in Photovoltaics: Research and Applications, 2002. 10(8): p. 555-570.

25. SKM MMA, Value of Generation from Small Scale Residential PV Systems, 2011, Sinclair Knight Merz MMA: Final Report to the Clean Energy Council, Melbourne.

26. McHenry, M.P., Are small-scale grid-connected photovoltaic systems a cost-effective policy for lowering electricity bills and reducing carbon emissions? A technical, economic, and carbon emission analysis. Energy Policy, 2012. 45(0): p. 6472.

27. Breyer, C. and A. Gerlach, Global overview on gridparity. Progress in Photovoltaics: Research and Applications, 2013. 21(1): p. 121-136.

28. Kind, P., Disruptive Challenges: Financial Implications and Strategic Responses to a Changing Retail Electric Business, 2013, Energy Infrastructure Advocates. Prepared for Edison Electric Institute.

29. Hammond, G.P., et al., Whole systems appraisal of a UK Building Integrated Photovoltaic (BIPV) system: Energy, environmental, and economic evaluations. Energy Policy, 2012. 40(0): p. 219-230.

30. Yamamoto, Y., Pricing electricity from residential photovoltaic systems: A comparison of feed-in tariffs, net metering, and net purchase and sale. Solar Energy, 2012. 86(9): p. 2678-2685.

31. IEA, Technology Roadmap Smart Grids, 2011, International Energy Agency: Paris, France.

32. US Department of Energy, Smart Grid System Report, 2009, U.S. Department of Energy.

33. US Department of Energy, Smart Grid Investment Grant Program, Progress Report, 2012, U.S.Department of Energy.

34. Elab, New Business Models for the Distribution Edge The transition from Value Chain to value 
constellation, 2013, The Electricity Innovation Lab. Rocky Mountain Institute.

35. Oliva, S.J. and I.F. MacGill. Estimating the economic value of distributed PV systems in Australia. in Innovative Smart Grid Technologies Asia (ISGT), 2011 IEEE PES. 2011

36. IPART, Solar feed-in tariffs - Setting a fair and reasonable value for electricity generated by smallscale solar PV units in NSW, 2012, Independent Pricing and Regulatory Tribunal: Final Report, prepared for the NSW government, Sydney.

37. AEMC, Power of choice review - giving consumers options in the way they use electricity. Final Report, 30 November 2012, Sydney, 2012.

38. IPART, Solar feed-in tariffs Retailer contribution and benchmark range for 1 July 2012 to 30 June 2013, 2012, Independent Pricing and Regulatory Tribunal: Electricity - Determination, NSW.

39. Dunstan, C., et al., Think Small: The Australian Decentralised Energy Roadmap: Issue 1, December 2011, 2011, CSIRO Intelligent Grid Research Program. Institute for Sustainable Futures, University of Technology Sydney.

40. Passey, R.J., et al., Study of grid-connect photovoltaic systems: benefits, opportunities and strategies. Progress in Photovoltaics: Research and Applications, 2009. 17(6): p. 419-431.

41. Yan, W., et al. Operation Strategies in Distribution Systems with High Level PV Penetration in ISES Solar World Congress 2011, Kassel. 2011.

42. Green Energy Markets, Small-scale technology certificates data modelling for 2013 to 2015, Report to the Clean Energy Regulator, 2013, Green Energy Markets. Available online at http://ret.cleanenergyregulator.gov.au/About-theSchemes/Administration/Reports/reports. accessed 15-07-13.

43. AER, Annual volume weighted average spot prices. Australian Energy Regulator <www.aer.gov.au/node/9756> accessed 15-7-2013, website.

44. Australian Treasury, Chart and Table Data - Chapter 5: Australia with carbon pricing. $<$ http://archive.treasury.gov.au/carbonpricemodelling /content/chart_table_data/chapter5.asp> accessed 1507-2013, website.

45. AEMO, List of regional boundaries and marginal loss factors for the 2012-13 financial year. Australian Energy Market Operator. Prepared by the Electricity System Operations Planning \& Performance, 2012.

46. AEMO, Distribution loss factors for the 2012 / 2013 financial year. Australian Energy Market Operator. Prepared by the Metering and Settlements, 2012.

47. Endeavour Energy, Network Price List 2012/2013, 2012, Endeavour Energy.

48. Origin Energy, NSW RESIDENTIAL Energy Price Fact Sheet (Effective 1 July 2012). <http://www.originenergy.com.au/files/necf/NSW_El ectricity_Residential_Endeavour\%20Energy\%20(For merly\%20Integral\%20Energy)_Standard\%20Publish ed\%20Rate.PDF> accessed 15-07-13, website.

49. Endeavour Energy, Annual Pricing Proposal 2012/13, 2012, Endeavour Energy.

50. IPART, Changes in regulated electricity retail prices from 1 July 2012, 2012, Independent Pricing and Regulatory Tribunal: Final Report prepared for the NSW government, NSW.
51. Ausgrid, Demand Management Investigation Report, Warringah STS, 2007, http://www.ausgrid.com.au/search.aspx?q=warringah accessed 15-7-2013.

52. Consulting, F., Audit of Integral Energy's D-Factor Claim for FY09/10, 2011, Final Report to Integral Energy, Jan. 2011.

53. Lewis, S.J. Analysis and management of the impacts of a high penetration of photovoltaic systems in an electricity distribution network. in Innovative Smart Grid Technologies Asia (ISGT), 2011 IEEE PES. 2011.

54. Australian Goverment, Energy White Paper 2012, Australia's energy transformation, 2012, Department of Resources, Energy and Tourism. Australian Goverment. Available online at www.energywhitepaper.ret.gov.au. accessed 15-7-13.

Acknowledgments

The authors gratefully acknowledge the contributions of Simon Lewis in helping provide PV output data from residential houses connected to the Endeavour Energy distribution system. This work is supported in part by Australian Solar Institute (now the Australian Renewable Energy Agency, ARENA) research funding to support research on solar forecasting and renewable energy integration and managing high PV penetrations. 